\title{
The Effect of Social Networking on the Divorce Process*
}

\author{
Betül Aydın ${ }^{1, *}$, Serkan Volkan Sarı ${ }^{1}$, Mustafa Şahin ${ }^{2}$ \\ ${ }^{1}$ Department of Psychological Counseling and Guidance, Faculty of Education, Recep Tayyip Erdoğan University, Rize, Turkey \\ ${ }^{2}$ Department of Psychological Counseling and Guidance, Faculty of Education, Karadeniz Technical University, Trabzon, Turkey
}

Copyright $\mathrm{O} 2018$ by authors, all rights reserved. Authors agree that this article remains permanently open access under the terms of the Creative Commons Attribution License 4.0 International License

\begin{abstract}
This study aims to examine the opinions of people who have divorced because of their spouses' relationships on social network, and who stated that they were deceived by their spouses on internet. In the study, case study method was used since the study deals with "the people who have divorced for their spouses deceived them on the internet". The study was carried out with ten participants (five of them are male and five of them are female) living in Trabzon, Turkey and divorced in 2013 for they were deceived by their spouses in social networking websites. Data were collected by recording of the interviews carried out with semi-structured interview protocol. Data gathered by the recordings device of the interview protocols were written down. In the process of data analysis, "constant comparative analysis" was employed. Findings of the study were collected into two main categories. The first was about the types of the participants' spouses' using social networks and the second about the effects of the messages and sharings of the spouses in social networks on familial relations. The findings of the study showed that the ways spouses used social networks affected the marriage negatively. According to another finding of the study, it can be said that from the aspects of emotional, behavioural, social and psychological aspects, use of the social networks by the divorcees' spouses affected the inter-family relationships. Certain suggestions were made based on these findings.
\end{abstract}

Keywords Infidelity, Internet, Marriage, Social Networking

\section{Introduction}

The internet is nowadays seen as an important and easy tool for individuals to start and develop relationships and is also used extensively for these purposes [1]. Individuals are able to meet people from different cultures, different countries, different genders and different professions. It is possible to meet such people and develop a relationship with them at any time of the day without spending too much money, time and effort [2]. Such relationships create opportunities for some to feel safe and free and get rid of the demands and hardships of daily routines and break free from a lonely and isolated social life $[3,4]$. Nonetheless, when the internet is used by people who already have a romantic relationship or are married in real life in order to develop and build up a new relationship, this can cause serious problems [5]. Even though pursuing a relationship online might seem harmless to those who actually do it, due to the fact that they do not have any physical contact with anybody [6], the situation is taken seriously by the real life partners, a situation in which their partner is likely to have physical contact with somebody else, and therefore it can be said that online relationships are also considered "cheating" [7, 8, 9]. Online cheating, in other words "cyber-cheating", can be stated as a situation in which the partner, husband or wife, has romantic and sexual affairs on the net, dating sites, e-mail groups, interactive games, chat-rooms or newsgroups [4]. Whitty [10] criticizes the emphasis on sexuality in "cyber-cheating" and refers to the emotional intimacy in the relationship that has been developed online and the devastating effects it has on the relationship in real life. According to the results of relevant research, it can be said that cyber-cheating can include different kinds of behaviour according to the perception of the couples, varying from joking around with somebody on the internet, making compliments, going ahead with somebody online, developing emotional intimacy, to fulfilling needs which are not fulfilled in the actual real life relationship and having sexual intercourse [3].

Cyber-cheating has many effects on the real life relationship of the individual. It affects the deceived partner and even the family negatively if there is the case of a marriage in the given circumstances. The deceived partner feels a sense of shame and guilt and loses his trust in the relationship with the deceiving partner. The person who has been cheated deeply experiences the feelings of being hurt, shame, guilt, anger, rejection and loneliness. The online relationship gains more and more importance than the real life relationship which causes harm to the sexual intimacy between the partners in real life. Partners share less with each other as time passes, communication 
and conflict problems have a negative effect on the resolution process and the feelings of trust and being a whole in a relationship are harmed. Children are ignored; they face concentration problems and can from time to time be exposed to internet sites like pornographic ones whose contents are for only adults $[1,4,5,10,11,12]$.

It is stated that the most common reason for divorce in America is the online cheating of married couples and that in one out of three divorce files, the word "Facebook" appears as a reason [13]. In terms of the number of the Facebook users, Turkey ranks $20^{\text {th }}$ in the world and comes second at the tables of Europe [14] and as in America, the divorce rate in Turkey due to internet abuse is getting higher and higher [15]. There are research studies on online-cheating carried out with college students who have (or not have) had a romantic relationship examining their perspectives on which activities could be considered to be actions of cheating and which are not [e.g. 3, 6, 10, 16, 17]. Based upon what has been done on this issue, it is possible to say that studies in the literature about online-cheating concerning married couples are limited [e.g. 7, 8].

This study aims to dwell on the opinions of married people who have divorced because of the relationships on social network, and who stated that they were deceived by their partners on internet. Their opinions have been qualified according to their answers to the following questions:

1. In what way your partner has been using the net so that you think (s)he is deceiving you?

2. What are the effects of this kind of internet abuse on family relations?

\section{Method}

This study is a case study since it deals with "the people who have divorced just because their partners deceived them on the internet". Case studies are mostly considered to use a qualitative research methodology and the most definite feature of qualitative research is that it is used for the studies focusing on current facts, events, statements, individuals and groups [18]. In this study, the situation of the participants that they were deceived on the internet by their partners is considered as "case" and examined in depth. By the fact that case studies requires in depth examination [19], the sample size is limited to ten participants.

\subsection{Participants}

The study was carried out with ten participants (five of them are male and five of them are female) living in Trabzon, Turkey and divorced in 2013 for they were deceived by their spouses in social networking websites. The study employed the convenience sampling to choose the participants. This sampling method is used frequently in various research studies especially when reaching the subjects is very difficult [18].

The ages of participants were between 25 and 44 . The span of their marriages was between 2 and 20 years. Participants were selected in the city of Trabzon and all of them had Turkish origin. The participants viewed themselves belonging to the middle socioeconomic class. The duration of being a member of social networks of participants was between 2 and 15 years, while their partners' were 3 and 12 years. The time of daily use of social networks of participants changed between 30 minutes and 4 hours while their partners' were between 2 and 18 hours. Participants largely stated that the main cause of the divorce is infidelity and distrust. Sociodemographic characteristics of the participants are presented in Table 1. 
Table 1. Sociodemographic Information about the Participants

\begin{tabular}{|c|c|c|c|c|c|c|c|c|c|}
\hline & Age & Gender & $\begin{array}{c}\text { Perceived } \\
\text { socioeconomic } \\
\text { status }\end{array}$ & $\begin{array}{l}\text { The span } \\
\text { of } \\
\text { marriage }\end{array}$ & $\begin{array}{l}\text { The span of } \\
\text { membership } \\
\text { of the } \\
\text { participants } \\
\text { in social } \\
\text { network } \\
\text { (Year) }\end{array}$ & $\begin{array}{c}\text { The span of } \\
\text { membership } \\
\text { of } \\
\text { participants' } \\
\text { partners in } \\
\text { social network } \\
\text { (Year) }\end{array}$ & $\begin{array}{l}\text { The time of } \\
\text { daily use of } \\
\text { social } \\
\text { network of } \\
\text { participants }\end{array}$ & $\begin{array}{c}\text { The time of } \\
\text { daily using } \\
\text { social network } \\
\text { of } \\
\text { participants' } \\
\text { partners }\end{array}$ & $\begin{array}{c}\text { Reasons of } \\
\text { divorce }\end{array}$ \\
\hline $\mathrm{P} 1$ & 37 & M & Middle & 10 & 7 & 8 & 2 hours & 10 hours & $\begin{array}{c}\text { Infidelity, } \\
\text { Distrust }\end{array}$ \\
\hline $\mathrm{P} 2$ & 33 & M & Middle & 6 & 6 & 3 & 30 minutes & 12 hours & $\begin{array}{c}\text { Infidelity, } \\
\text { Distrust }\end{array}$ \\
\hline $\mathrm{P} 3$ & 35 & M & Middle & 11 & 5 & 4 & 1 hour & 18 hours & Infidelity \\
\hline $\mathrm{P} 4$ & 40 & M & Middle & 20 & 4 & 4 & 1 hour & 2 hours & $\begin{array}{c}\text { Dissensions, } \\
\text { Distrust }\end{array}$ \\
\hline P5 & 25 & $\mathrm{~F}$ & Middle & 2 & 4 & 6 & 1 hour & 4 hours & $\begin{array}{l}\text { Infidelity, } \\
\text { Jealousy, } \\
\text { Distrust, } \\
\text { Omission, } \\
\text { Severity }\end{array}$ \\
\hline P6 & 44 & $\mathrm{~F}$ & Middle & 19 & 8 & 12 & 30 minutes & 5 hours & $\begin{array}{l}\text { Infidelity, } \\
\text { Distrust, } \\
\text { Neglecting, } \\
\text { Dissensions }\end{array}$ \\
\hline $\mathrm{P} 7$ & 36 & $\mathrm{~F}$ & Middle & 6 & 2 & 10 & 1 hour & 8 hours & $\begin{array}{l}\text { Infidelity, } \\
\text { Omission }\end{array}$ \\
\hline P8 & 39 & $\mathrm{~F}$ & Middle & 12 & 15 & 6 & 1 hour & 3 hours & $\begin{array}{l}\text { Infidelity, } \\
\text { Omission }\end{array}$ \\
\hline P9 & 35 & M & Middle & 9 & 3 & 9 & 4 hours & 13 hours & Infidelity \\
\hline P10 & 29 & F & Middle & 3 & 8 & 10 & 4 hours & 6 hours & Omission \\
\hline
\end{tabular}

\subsection{Data Collection Process}

Data were collected by recording the interviews carried out with semi-structure interviews protocol. In the first section of the protocol, there were sociodemographic information questions about participants (age, sex, socio-economic status, the span of marriage, the duration of being a member of social networks and using time per day, and the reasons of divorce). In the second section, the ways and types the participants use the net and their effects on their family relations and divorcing process are given. The questions designed were examined by three academicians in terms linguistic and semantic considerations and were corrected in accordance with the feedbacks. Peer debriefing is one of the precautions on such kind of research studies [18]. Afterwards, the piloting of the interview protocol, comprising of 5 persons who divorced because of similar reasons and the intelligibility of the questions were tested. The last form of the interview protocol was made by taking 18 questions out which were found meaningless and redundant. Within the context of the study, the interviews were conducted with ten persons on different weekdays. Interviews were made face-to-face in the offices of the researchers. Interviews took 75-90 minutes.

\subsection{Data Analysis}

Data gathered by the recordings of the interview protocols were written down. In the process of data analysis, "constant comparative analysis" method, used in qualitative studies, was employed. In this method, the data is compared applicable to each code and the code definitions are modified to fit new data [18]. By this analysis, statements of all participants were written down. The gathered headings were categorised and explicated by the researchers. Findings were supported by taking direct citations from the speeches of the participants.

\section{Findings}

Findings of the study were put into two main categories. The first was about the ways the participants' partners use the internet and the second about the effects of the messages and posts of the partners on the net on familial relations.

\subsection{The Ways the Divorced Partners Use Internet}

The first finding of the study defined the types and the ways the partners of the participants use the net. The answers of the participants were categorised and stated in Table 2. 
Table 2. The types of using social network of the partners of the participants

\begin{tabular}{|c|c|}
\hline Opinions & Participants \\
\hline $\begin{array}{c}\text { Using social networks secretly and blocking } \\
\text { the partner }\end{array}$ & P2, P5 \\
\hline Sending messages via more than one account & P3, P4, P8 \\
\hline Sending messages by hiding the real identity & $\begin{array}{c}\text { P1, P2, P5, P6, P7, } \\
\text { P9, P10 }\end{array}$ \\
\hline $\begin{array}{c}\text { Sending messages to the same person or with } \\
\text { the same opposite sex }\end{array}$ & P1, P5, P9 \\
\hline Hiding relationship status (marital status) & P5, P6, P8, P10 \\
\hline
\end{tabular}

As is seen in Table 2, participants stated that their partners shared their posts and messages in the social networks as if they were a different person. The participants also stated that they shared in social network with the same person or the opposite sex and hide their relationship status, using different accounts in social networks.

Upon examining Table 2, it can easily be seen that the most frequently encountered sharing type of the partners in social networks is personation. P10 described this situation as follows:

"His/her sharing personal information (age, birth place, relationship status, hobby, photo, books etc.) differently caused me to suspect. Which one is imaginary? The one I live with or the one I meet in social networks. I don't know. After I realized this situation, we became strangers day by day."

In relation to this situation, participants stated that their partners ignored or hid the information about their marriage status. In addition to this, P10 stated this situation as follows:

"My partner always left his/her marriage status empty on Facebook. I warned him/her and asked him/her to change the status as married but he/she didn't do this."

Participants stated that their partners uploaded false personal information (relationship status, age, physical appearances, hobbies etc.). In other words, they shared on social networks with fake accounts and as a result of this, their marriages were affected negatively. Participants also reported that some problems occurred between family members in consequences of having unreal accounts on social networks and sharing with other people.

\subsection{Effects of Social Media Usage on Family Relations}

Another finding of the study is about the effects of the use of social media on family members. Answers given by the participants were divided into four groups and shown in Table 3.

Given Table 3, using social network affects relations between spouses and other family members in four categories. Lack of love and affection between family members are categorised in terms of emotional aspect, particularly having violence behaviour, scolding children and having spurious indiscreet affairs are categorised in terms of behavioural aspect, lack of domestic communication and cooperation and not fulfilling responsibilities are categorised in terms of social aspect and feeling alone, abasement and having depressive behaviours are categorised in terms of psychological aspect.

Table 3. Opinions of the Participants about the Effects of the Use of Social Media on Family Relations

\begin{tabular}{|c|c|c|}
\hline Categories & Opinions & Participants \\
\hline \multirow{3}{*}{$\begin{array}{c}\text { Emotional } \\
\text { Aspect }\end{array}$} & Damage to emotional relations & P1, P4 \\
\cline { 2 - 3 } & Lovelessness and apathy against children & P2, P7 \\
\hline \multirow{3}{*}{$\begin{array}{c}\text { Behavioural } \\
\text { Aspect }\end{array}$} & It is unforgivable & P2, P5, P9, P10 \\
\cline { 2 - 3 } & Forbidden love affairs via social media & P2, P3, P9 \\
\hline \multirow{3}{*}{\begin{tabular}{c} 
Social Aspect \\
\cline { 2 - 3 }
\end{tabular}} & Negative impacts on children & P1, P2, P6 \\
\cline { 2 - 3 } & Physical and verbal violence & P5, P6 \\
\hline $\begin{array}{c}\text { Psychological } \\
\text { Aspect }\end{array}$ & Ignoring responsibilities & P5, P6, P7 \\
\hline
\end{tabular}


In Table 3, negative effects of using social network were shown in terms of "social aspect" by the majority of the participants. In other words, according to participants, the style of using social networks caused the impairment of social surroundings in the family. P9 stated this situation with these words:

"My partner finished our marriage by having a friend, darling on the net. Our relationship became asocial for he spent hours in front of computer screen, we stopped going out to take a walk, going to cinema and spending time together."

Similarly, P6 stated that using social network affected social relationships in negative ways by saying:

"I and my daughter are a team; my partner and the computer are another team at home"

Using social network is associated with the lack of love and concern in family in "emotional aspect". For instance, P2 expressed his ideas about how his partner's over using or abuse of social network caused sensual distress in him as follows:

"Social media destroyed my marriage and my life, firstly it began with arguments, then lack of interest in children and I have cheating partner... I will not forgive her."

In terms of "behavioural aspect", some of the participants stated that violence came into prominence in family surroundings. Nonetheless, these aspects are not beside the point from each other. In other words, corruption in behavioural aspects affect social structure of the family and psychological statement of spouses in negative way or just opposite of that is a matter sometimes. Statement of P5 is an important example for this situation:

"Firstly, familial responsibilities were gone and then hidden things started. As a partner and as a lady I felt abased, pessimism, depressed and searching for inadequacy in myself... When I started to questioning, I faced with violence. When I decided to divorce, he asked me to forgive him, then when I did not accept, I was exposed to violence and abasement again."

As it was seen in Table 3, participants stated that having relationships which are not appropriate for a married person, which means using social networks for inappropriate purposes, resulted in leaving from their partners, and negative and devastating effects on their marriage and personality in terms of sensual, behavioural, social and psychological aspects.

The participants have indicated that these effects mostly take place in the "social aspect" and pointed out that spouses who use social networks for hours for unacceptable purposes lead to marital breakdown caused by poor familial relationships, and lack of joint - social activities, etc.

When it is considered that marriage is a relationship which is based on emotions and communication and knowing how important "joint activities" and "effective communication" are to make a healthy relationship work, then it should be taken into consideration that findings of this research can be seen as significant. Also participants pointed out that with the misuse of the social networks by their spouses, they felt neglected, disregarded, loveless, both emotionally and behaviourally cheated, subjected to violence, insecure, lonely, inferior and psychologically sick, which ended their relationships for they did not forgive their partners. When it is considered what the participants went through in this process, it can be seen that the principle of "commitment", which is very important in marriage, has vanished. In marriage, spouses should be loyal to each other, feed and protect the basic emotions and values like love, respect, patient, loyalty, trust, etc. give meaning to their lives. So the disappearance of such values and emotions make the relationship meaningless and make the divorce unavoidable

\section{Discussion and Conclusions}

In this research, using social networks' effects on familial relationships and divorce process has been examined. The first finding was that the ways spouses used social networks affected the familial relationships negatively. That the posts by the participants' spouses on the net made affected marriages negatively can be understood from the views of the participants. In literature, there are many studies which examine the effects of using social networks on couples. Among these, the most prominent one is the negative effects of misuse of the social networks on relationships [20,21]. Beside this, it is stated that the use of social networks obsessively or addictively decreases the quality of communication in marriages [22]. According to Kuss and Griffiths [23], addictive use of social networks, individuals' negligence of their responsibilities in personal life [24] having a busy mind [25], cause psychological problems like escapism [3]. In another research study, it is reported that the over usage of Facebook in USA between 2008 and 2010 increased the rate of divorces [26, 27]. Also, according to Elphinstone and Noller [26], the obsessive use of social networks causes couples to be ashamed of each other because of the behaviours which can reduce the qualities of the relationship, like reconnecting with people who they formerly relationships with in real life.

One of the negative effects of the social networks is the individual's ability to share different things via an internet account. With the findings which are consistent with the wishes of the participants to check the account of their spouses, it can be seen that the opportunity which social networks give to their users like being anonymous and showing themselves with different identities, affects individuals' communication styles. The offerings like marital status, age, physical appearances, and hobbies of social networks which can be reflected differently from real world have shaken participants' trust in their partners and affected the commitment in their marriage negatively. 
One participant (P10) stated as follows: "My partner shared his/her personal information (age, place of birth, marital status, hobby, photo, books, etc.) very differently and it made me suspicious. We became strangers day by day after I noticed it". With this, the posts and messages in the social networks performed with the opposite sex and using false accounts can be taken as a violation of trust and loyalty. So, it can be considered that it is effective in the decision of divorce between couples because of the loss of the trust and loyalty.

According to the second finding of the research, it can be said that from the aspects of emotional, behavioural, social and psychological aspects, use of the social networks by the divorcees affected the familial relationships. In this regard, the first and most effective aspect is the social one. The most seen problems in the social aspect are deterioration in inter-family relationships and restriction in mutual sharing area by the misuse of the social networks. According to Valenzuela et al. [27], addictive use of the social networks has an economic and psychological effect on the quality of spouses' marriage and it decreases the quality of the marriage. Researches show that people spend more time day by day in this virtual world and try to support their real life needs and build a new life there $[8,17$, 28]. Similarly, some studies prove that social networks have a negative effect in spouses' relations and decrease the quality of their communication $[20,26]$, caused negligence of their cooperation [29] and responsibility [23]. One of the participants (P9) reported that: "My partner had an online love affair and it caused our divorce. Our relationship became lame while my partner spent more and more time in front of the computer and forgot about the habit of going out or going to a movie." One of the essential parts of the marriage is having a motivation in sharings and act together in familial relationships. It is very important to take mutual decisions and apply them in family relationships [30]. Members of the family take different parts of this identity. These roles form the mutual sharing area of the inter-family relationships. According to Becvar and Becvar [31], when an individual meets the sexual, emotional and physical needs via the relationship in the family, it increases the individual's self-improvement or family bounds. It stops the improvement of the family identity, if one of the members of the family ignores their duties and this damages the bounds and relationships within the family. As a result, this effect can be considered as a reason for the divorce between spouses.

The second aspect of the divorce was the emotional one. Participants made a connection between the decrease in love and attention in inter-family relations and the use of social network. Research shows that individuals have intrinsic satisfaction in emotions like emotional support [32], belonging and encouragement [33]. Individuals can fulfil their social and sexual needs on the internet and neglect their relations in real life [24]. One of the participants claimed that (P2): "Social networks destroyed my marriage and life. First the arguments started, then apathy to the children and at the end cheating. I will never forgive". Emotional signals had a central role in inter-family relationships. There is an important association between these signals and the aspect of the spouses' relationship [30]. The intensive emotion between spouses has an effect on satisfaction of the relationship. In this sense, misuse of the social media is considered to be damaging the emotional bounds like love and care between spouses. It can be stated that this case is effective on divorces.

The third aspect was the behavioural one. In this case, it can be understood from the views of participants that violence stood out in the family environment. According to research, the behaviours occurred during the usage of social networks could differ from the point of individuals. For example, men used the internet more than women and women's capability of using a computer seemed to be lower [34]. That men become more addicted to several kinds of internet addictions (gambling, pornography or game addiction via internet) might be demonstrated as a reason of this as well $[35,36]$. It has been specified that social networks lead to certain behavioural changes like having indiscreet affair [9] being irresponsible and apathetic toward family members [23]. Such crises between couples might occasionally turn into violence. Also, there are a myriad of forms of domestic violence like slapping, pushing and throwing objects; the worst is beating including various physical assaults and serious physical injuries [37]. Male characters using violence against woman are different from each other, and one and all are predicated on particular reasons. Here, the problem is chronic, dysphoric and effective situations beginning with men's use of social networks and following on anxiety, anger, fear, shame and family unrest and potential depression combined with stress [38]. It is also clearly seen that the aforementioned male character reflects on expressions of a participant (P5): "Responsibilities at home were neglected at first and he started to do something hidden from me. As a wife and a woman, I felt inferiority complex, pessimism, depressed, and searched for my imperfections. I was subjected to violence when I started questioning. He begged my pardon when I was determined to divorce, but after I rejected his excuse, I was exposed to violence and humiliation again." In basic family structure, one of the most important principals is affection and respect. Violence means that these two significant principles between couple are destroyed. Here, it is asserted that after being caught by the other half, anger, fear, shame and regret felt by partner who uses social media too much and addictively might have the results that sometimes turn into violence. Besides, it is considered that this situation becomes more effective upon the divorcement of couples who participated in the research.

The last aspect is psychological aspect. According to the results, it is revealed that participants had the feelings of 
depression, abasement, lack of confidence and loneliness because of using social networks. Kuss and Griffiths [23] set forth that using social networks at the level of addiction causes an individual to have psychological problems like ignoring responsibilities in personal life, having a busy mind and escapism. Furthermore, it is ascertained that there are significant relationships between loneliness [39] and depressive behavioural tendencies [27] resulting from using social networks. Unexpected psychological attitudes in family structure exert unfavourable disruptive effects on the routines of families [31]. On this topic, a participant reported the following (P5): "As long as my husband got round to social media, he suddenly stopped fulfilling his responsibilities. I felt lonely and abased. I succumbed to depression..." Certain events in family life are likely to be surprising for family members and cannot be controlled. Those abrupt actions influence family happiness negatively. As a result of this, dealing with psychological intensity and sufferings is probable [31]. This situation can be evaluated as a psychological trauma for partner who finds out that the other half uses social network secretly for particular reasons. It has significant influence on divorcements.

Consequently, perpetual use of social networks by one of the partners for secret purposes creating fake profiles elicits negative impacts on family health and togetherness in social, emotional, behavioural and psychological aspects, and it is seen that this situation plays a crucial role in divorcements. This study had some limitations. The researchers had an interview with participants individually. The participants expressed their experiences mostly concerning Facebook social networking site. Another point is that the collected data within the scope of the research was limited to the outcomes gathered by using only interview method.

Certain suggestions can be made based on the results from this study. Primarily, specifying problems in the married people's habits of using social media and developing solutions are significant in terms of avoiding damages in love and trust in relations between married couples. In this sense, studies with survey method can be organized to specify problems in the abusive use of social media between married people. Besides, some certain panel discussions and conferences can be organized by specialists to help people develop correct habits of using social media. Negative effects of social media on families can be straightened before couples divorce. For this purpose, psycho-educational programs to refresh family relations, strengthen communication between couples, and solve family problems can be organized, and results of these programs can be shared by specialists in the field. Since this study is not experimental in nature, it is not exact if the use of social media in abusive way affected the marriage negatively or the existing problems directed deceiving partners to use the social media in abusive way to relieve these problems. Future studies could handle this issue by collecting the data about course of the marriage in terms of emotional, social, behavioural and psychological aspects and its effect on partners' abusive social media use.

\section{REFERENCES}

[1] K. M. Hertlein, \& F. P. Piercy. Internet cheating: A critical review of the literature. The Family Journal, Vol. 14, No:4, 366-371, 2006.

[2] K. M. Hertlein, F. P. Piercy. Therapists' assessment and treatment of internet cheating cases. Journal of Marital and Family Therapy, Vol.34, No: 4, 481-497, 2008.

[3] T. Docan-Morgan., C. A. Docan. Internet cheating: Double standards and the differing views of women and men. Communication Quarterly, Vol.55, No: 3, 317-342, 2007.

[4] M. M. Maheu. Women's Internet behavior: Providing psychotherapy offline and online for cyber-Cheating. Paper presented at the Annual Conference of the American Psychological Association, Boston, MA, 1999, August.

[5] H. Underwood, B. Findlay. Internet relationships and their impact on primary relationships. Behaviour Change, Vol.21, No:2, 127-140, 2004

[6] H. A. Groothof, P. Dijkstra, D. P. Barelds. Sex differences in jealousy: The case of Internet cheating. Journal of Social and Personal Relationships, Vol.26, No: 8, 1119-1129, 2009.

[7] J. D. Cravens, K. R. Leckie, J. B. Whiting. Facebook cheating: when poking becomes problematic. Contemporary Family Therapy, Vol.35, No: 1, 74-90, 2013.

[8] B. L. A. Mileham .Online cheating in Internet chat rooms: An ethnographic exploration. Computers in Human Behavior, Vol.23, No: 1, 11-31, 2007.

[9] M. T. Whitty. Cyber-flirting: Playing at love on the Internet. Theory and Psychology, Vol.13, No: 3, 339-357, 2003.

[10] M. T. Whitty. The realness of cyber cheating men's and women's representations of unfaithful internet relationships. Social Science Computer Review, Vol.23, No: 1, 57-67, 2005.

[11] Hertlein, K. M. Therapeutic dilemmas in treating internet cheating. The American Journal of Family Therapy, Vol.39, No: 2 162-173, 2011.

[12] J. P. Schneider. Effects of cybersex addiction on the family. In A. Cooper (Ed.), Cybersex: The dark side of the force (pp. 5-31). Routledge, Philadelphia, 2013.

[13] Lupkin, S. (2012). Can Facebook ruin your marriage? [Online] Available: http://abcnews.go.com/Technology/facebook-relationship-s tatus/story?id=1640624514

[14] Internet World Stats (2017).Top 20 Internet Countries. [Online] Available:

http://www.internetworldstats.com/top20.htm

[15] Sabah.com (2010). Dikkat başınıza gelmesin! [Attention! May it not happen to you][Online]Available:http://www.sabah.com.tr/teknoloji/2 010/08/14/facebook artik bosanma sebebi 
[16] J. Hackathorn, R. Harvey. Sexual double standards: Bias in perceptions of cyber-cheating. Sexuality \& Culture, Vol.15, No: 1, 100-113, 2011.

[17] M. T. Whitty, L. L. Quigley. Emotional and sexual cheating offline and in cyberspace. Journal of Marital and Family Therapy, Vol.34, No: 4, 461-468, 2008.

[18] S. J. Tracey. Qualitative research methods: Collecting evidence, crafting analysis, communicating impact. Wiley -Blackwell, West Sussex, 2013.

[19] D. M. Zucker. How to do case study research? In M. Garner, C. Wagner and B. Kawulich (Eds), Teaching research methods in the social sciences (pp.171-182). Ashgate Publishing, Burlington, 2009.

[20] M. M. Hand, D. Thomas, W. C. Buboltz, E. D. Deemer, M. Buyanjargal .Facebook and romantic relationships: Intimacy and couple satisfaction associated with online social network use. Cyberpsychology, Behavior, and Social Networking, Vol.16, No: 1, 8-13, 2013.

[21] E.Christofides, A. Muise, S. Desmarais. Information disclosure and control on Facebook: are they two sides of the same coin or two different processes?. CyberPsychology \& Behavior, Vol.12, No: 3, 341-345, 2009.

[22] J. Raacke, J. Bonds-Raacke. MySpace and Facebook: Applying the uses and gratifications theory to exploring friend-networking sites. Cyberpsychology, Behavior, and Social Networking, Vol. 11, 169-174, 2008.

[23] D. J. Kuss, M. D. Griffiths. Online social networking and addiction: A review of the psychological literature. International Journal of Environmental Research and Public Health, Vol. 8, 3528-3552, 2011.

[24] A. Cooper, I. P. McLoughlin, K. M. Campbell. Sexuality in cyberspace: Update for the 21st century. CyberPsychology \& Behavior, Vol.3, No: 4, 521-536, 2000.

[25] J. Y. Yen., C. H. Ko, C. F.Yen, S.H. Chen, W. L. Chung, C. C. Chen. Psychiatric symptoms in adolescents with Internet addiction: Comparison with substance use. Psychiatry and Clinical Neurosciences, Vol. 62, No:1, 9-16, 2008

[26] R. A. Elphinston, P. Noller .Time to face it! Facebook intrusion and the implications for romantic jealousy and relationship satisfaction. Cyberpsychology, Behavior, and Social Networking, Vol.14, 631-635, 2011.

[27] H. Valenzuela, D. Halpern, J. E. Katz. Social network sites, marriage well-being and divorce: Survey and state-level evidence from the United States. Computers in Human Behavior, Vol. 36, 94-101, 2014

[28] B. A. Vural, M. Bat. Social media as a new communication environment: A research on Ege University Faculty of Communication. Journal of Yasar University, Vol. 20, No: 5, $3348-3382,2010$.

[29] E. J. Helsper, M. T. Whitty. Netiquette within married couples: Agreement about acceptable online behavior and surveillance between partners. Computers in Human Behavior, Vol. 26, 916-926, 2010.

[30] R. Dallos, R. Draper. An introduction to family therapy: Systemic theory and practice. McGraw-Hill Education, Berkshire, 2012

[31] D. S. Becvar, R. J. Becvar. Systems theory and family therapy. University Press Inc., Maryland, 1999.

[32] N. B. Ellison, C. Steinfield, C. Lampe. Connection strategies: Social capital implications of Facebook-enabled communication practices. New Media \& Society, Vol.1, $1-20,2011$.

[33] J. L. Bender, M. C. Jimenez-Marroquin, A. R. Jadad Seeking support on facebook: a content analysis of breast cancer groups. Journal of Medical Internet Research, Vol. 13, No: 1, 1-16, 2011.

[34] H. Ono, M. Zavodny. Gender and the Internet. Social Science Quarterly, Vol.84, No: 1, 111-121, 2003.

[35] E. Garbarino, M. Strahilevitz. Gender differences in the perceived risk of buying online and the effects of receiving a site recommendation. Journal of Business Research, Vol.57, No: 7. 768-775, 2004.

[36] B. Traeen, T. S. R. Nilsen, H. Stigum. Use of pornography in traditional media and on the Internet in Norway. Journal of Sex Research, Vol.43, No: 3, 245-254, 2006.

[37] R. McDermott, J. H. Fowler, N. A. Christakis. Breaking up is hard to do, unless everyone else is doing it too: Social network effects on divorce in a longitudinal sample. Social Forces, Vol.92, No: 2, 491-519, 2013

[38] J. F. Benenson. Gender differences in social networks. The Journal of Early Adolescence, Vol.10, No: 4, 472-495, 1990.

[39] C. S. Ong, S. C. Chang, C. C. Wang. Comparative loneliness of users versus nonusers of online chatting. Cyberpsychology, Behavior, and Social Networking, Vol. 14, 35-40, 2011.

* This study was presented as oral presentation in 8th World Conference on Psychology, Counseling and Guidance which took place on April 28h -30th 2017 in Antalya, Turkey. 